\title{
Correlation of granulin expression in intracranial meningiomas to clinical parameters
}

\author{
CHOONG HYUN KIM, JIN HWAN CHEONG and JAE MIN KIM \\ Department of Neurosurgery, Hanyang University Guri Hospital, Gyomun-Dong, Guri Gyeonggi-Do 471-701, Korea
}

Received February 12, 2010; Accepted March 15, 2010

DOI: 10.3892/etm_00000077

\begin{abstract}
The granulins, a novel class of peptides from leukocytes, are growth factors that mediate cycle progression and the motility of epithelial and mesenchymal cells. They are also involved in tissue repair and tumorigenesis. We investigated granulin expression in intracranial meningiomas by reverse transcription-polymerase chain reaction and correlated its expression to clinical parameters. Seventy-nine patients who underwent tumor removal for intracranial meningiomas were included in this study. Granulin expression was analyzed in respect to clinical parameters including age, gender, tumor size and peritumoral brain edema (PTBE). Granulin was expressed in the tumors of 29 of $79(36.7 \%)$ patients with intracranial meningiomas, and its presence or absence was correlated to tumor size and PTBE volume. However, granulin expression did not vary significantly according to patient age or gender. Our data provide improved understanding about the clinical implications of granulin expression in intracranial meningiomas. Additionally, our information suggests a potential role for granulin as a molecular target in the management of meningiomas.
\end{abstract}

\section{Introduction}

Growth factors constitute a family of multifunctional proteins that play important roles in the growth, development and maintenance of tissues (1). However, they also promote malignant phenotypes by enhancing cellular proliferation, survival, migration, invasiveness, acquisition of new vasculature and the ability of tumor cells to escape detection by immune cells (2). Growth factors such as transforming growth factor- $\alpha$ (TGF- $\alpha$ ) and macrophage colony stimulating factor (m-CSF) have been shown to regulate meningioma growth. Several angiogenic growth factors including vascular endothelial growth factor,

Correspondence to: Dr Choong Hyun Kim, Department of Neurosurgery, Hanyang University Guri Hospital, Gyomun-Dong, Guri Gyeonggi-Do 471-701, Korea

E-mail: kch5142@hanyang.ac.kr

Key words: granulin, growth factor, meningioma, polymerase chain reaction
(VEGF), placental growth factor, hepatocyte growth factor/ scatter factor and basic fibroblast growth factor (bFGF), have also been shown to be potential factors in intracranial meningiomas (3-5).

The granulin family of growth factors are from leukocytes and are known to mediate cell cycle progression and the cell motility of epithelial and mesenchymal cells $(6,7)$. High levels of granulin expression have been found in several types of cancers including those of the kidney, brain and stomach (8-10). Overexpression of granulin has also been linked to the growth and tumorigenicity of human breast carcinomas $(11,12)$. Furthermore, granulin mRNA levels are elevated in high-grade primary brain tumors (9). Meningiomas are common brain tumors and most are benign in their pathology. However, meningiomas frequently accompany peritumoral brain edema (PTBE) associated with malignant brain tumors. Meningioma develops in the meninges and originates from a multiple layer of mesenchymal cells (13). Granulin, which is mostly expressed in epithelial cell tumors, has not previously been reported in intracranial meningiomas, and its clinical implication in meningiomas has not been verified.

In this study, we investigated granulin expression in intracranial meningiomas and analyzed the association of this growth factor with clinical parameters including demographic data, tumor size and PTBE volume.

\section{Materials and methods}

Patients. Samples were obtained from 79 consecutive patients who underwent surgical removal of brain tumors that were confirmed pathologically as meningiomas between October 2002 and August 2005. The patient group included 15 (19\%) men and $64(81 \%)$ women ranging in age from 16 to 84 years (median 59 years). Tumor size and PTBE volume were measured on pre-operative magnetic resonance (MR) images. The greatest anteroposterior (a) and lateral (b) diameters were obtained on axial contrast enhanced $\mathrm{T}_{1}$-weighted $\left(\mathrm{T}_{1} \mathrm{~W}\right)$ images, and the greatest height (c) of the tumor on the coronal contrast enhanced $\mathrm{T}_{1} \mathrm{~W}$ MR images was measured to calculate the tumor size. The PTBE volume was estimated in the same manner on $\mathrm{T}_{2}$-weighted $\left(\mathrm{T}_{2} \mathrm{~W}\right) \mathrm{MR}$ images. The volume was calculated by the formula $\mathrm{V}\left(\mathrm{cm}^{3}\right)=4 / 3 \times \pi \mathrm{abc}$.

Tumor specimens. Freshly excised meningioma tissues were collected during craniotomies for their resection or during 


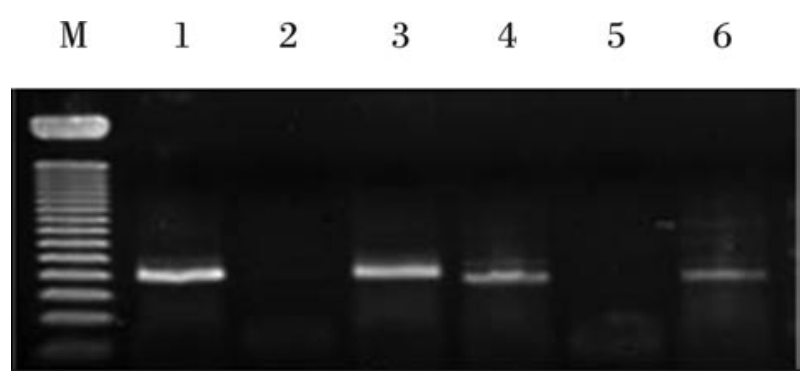

Figure 1. RT-PCR electrophoretic patterns displaying granulin expression in ethidium bromide-stained $2 \%$ agarose gel. Lanes 1, 3, 4 and 6 reveal granulin expression. M, 50-bp ladder.

biopsy. The tissues were stored quickly in a deep freezer at $-70^{\circ} \mathrm{C}$ prior to processing.

Reverse transcription-polymerase chain reaction (RT-PCR). Anonymized samples of frozen meningiomas were retrieved from the deep freezer, and RNA extraction was carried out using the SV Total Isolation system (Promega, Madison, WI, USA) according to the manufacturer's protocol. For each reverse transcription reaction, we combined $25 \mu$ l Access Quick Master Mix 2X (Promega), $1 \mu$ l upstream primer (5'-TCC ACG TGC TGT GTT ATG GT-3'), $1 \mu$ l downstream primer (5'-CTG CCC TGT TAG TCC TCT GG-3'), $5 \mu \mathrm{g}$ RNA template and nuclease-free water to a final volume of $50 \mu \mathrm{l}$. AMV reverse transcriptase $(1 \mu \mathrm{l})$ was added to the above mixture as the final component and mixed by gentle vortexing. Reaction tubes were incubated at $45^{\circ} \mathrm{C}$ for $45 \mathrm{~min}$. The PCR reaction was carried out using $3 \mu \mathrm{l}$ of the reverse transcription reaction product. Thirty-five cycles of touchdown PCR were performed according to the manufacturer's protocol and consisted of $95^{\circ} \mathrm{C}$ for $3 \mathrm{~min}$, a one-degree decline in annealing temperature $55^{\circ} \mathrm{C}$ for $1 \mathrm{~min}$, extension reaction at $72^{\circ} \mathrm{C}$ for $6 \mathrm{~min}$ and then maintaining the reaction at $4^{\circ} \mathrm{C}$ overnight. After that, PCR products were stored at $-20^{\circ} \mathrm{C}$. A single reaction void of template was performed with each experiment as a negative control. After mixing $8 \mu \mathrm{l}$ of PCR products and $2 \mu \mathrm{l}$ of loading buffer, mixtures were electrophoresed on a $2 \%$ agarose gel, stained with ethidium bromide and visualized by ultraviolet illumination (Fig. 1). The optical density (OD) for granulin mRNA concentration was measured by spectrometry, and its ratio to $\beta$-actin concentration was obtained.

Statistical analysis. Data were analyzed using SPSS version 11 (SPSS Inc., Chicago, IL, USA). The Student's t-test was employed to compare the differences in tumor size and PTBE volume between the granulin-positive and -negative tumors. Correlations of mRNA concentrations to tumor and PTBE volumes were analyzed by Pearson's correlation test. All data are expressed as the mean \pm standard deviation. Differences with a P-value of $<0.05$ were regarded as statistically significant.

\section{Results}

Patient characteristics. Granulin was expressed in tumors of $36.7 \%(n=29)$ of the patients with meningioma. The mean age of patients who were positive for expression of granulin
Table I. Patient characteristics and granulin expression in 79 patients with meningioma.

\begin{tabular}{lccr}
\hline Factors & \multicolumn{2}{c}{ Granulin expression } & P-value \\
\cline { 2 - 3 } & $(+)$ & $(-)$ & \\
\hline Mean age (years) & $53.7 \pm 1.6$ & $58.4 \pm 16.4$ & 0.149 \\
Gender & & & \\
Male (n=15) & $5(33 \%)$ & $10(67 \%)$ & $>0.050^{\mathrm{a}}$ \\
Female (n=64) & $24(38 \%)$ & $40(62 \%)$ & \\
Mean tumor volume $\left(\mathrm{cm}^{3}\right)$ & $51.5 \pm 5.9$ & $24.9 \pm 2.8$ & $<0.050$ \\
Mean PTBE volume $\left(\mathrm{cm}^{3}\right)$ & $104.2 \pm 15.9$ & $52.9 \pm 10.6$ & 0.010 \\
\hline
\end{tabular}

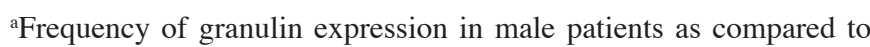
female patients.

was $53.7 \pm 1.6$ years and $58.4 \pm 16.4$ years for patients with granulin-negative tumors. The difference in ages between the two groups was not statistically significant $(\mathrm{P}>0.05)$. Granulin was expressed in 24 of 64 female patients (37.5\%) and in 5 of 15 male patients (33.3\%). The frequency of granulin expression according to gender was also not significantly different $(\mathrm{P}>0.05)$ (Table I).

Correlation of tumor volume and granulin expression. The mean tumor volume for all of the patients was $34.7 \pm 3.1 \mathrm{~cm}^{3}$. The mean tumor volume for the 50 patients with granulin-negative tumors was $24.9 \pm 2.8 \mathrm{~cm}^{3}$, whereas the average volume for patients with granulin-expressing tumors was $51.5 \pm 5.9 \mathrm{~cm}^{3}$, which was a statistically significant difference $(\mathrm{P}<0.05)$ (Fig. 2A). The relative ratio of OD for granulin detected in granulin-expressing tumors was $0.57 \pm 0.47$ (range 0-1.58), but it did not correlate to tumor volume $\left(\mathrm{R}^{2}=0.04, \mathrm{P}>0.05\right)$ (Fig. 2B).

Relationship between PTBE volume and granulin expression. The mean PTBE volume for all of the patients was $71.7 \pm 9.3 \mathrm{~cm}^{3}$. The mean PTBE volume was $52.9 \pm 10.6 \mathrm{~cm}^{3}$ in patients whose tumors did not express granulin expression, while it was $104.2 \pm 15.9 \mathrm{~cm}^{3}$ in patients with granulin-positive tumors. This marked difference in PTBE volume according to granulin expression was also significant $(\mathrm{P}<0.05)$ (Fig. 3A). However, as with tumor volume, the relative amount of granulin did not correlate to PTBE volume $\left(\mathrm{R}^{2}=0.01, \mathrm{P}>0.05\right)$ (Fig. 3B).

\section{Discussion}

We observed granulin expression in the intracranial meningiomas and found that it correlated to tumor size and PTBE volume. However, the differences we observed in granulin expression according to the demographic factors of age and gender were not significant.

Growth factors identified to date, such as TGF- $\beta$, m-CSF and lysophosphatic acid have been shown to replicate cancer cell growth and survival in vitro and in vivo (15-19). The role of growth factors in intracranial meningioma development 
A

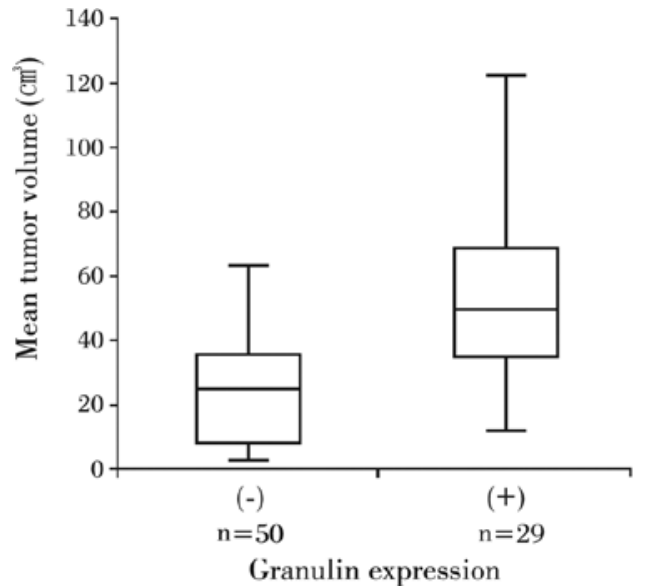

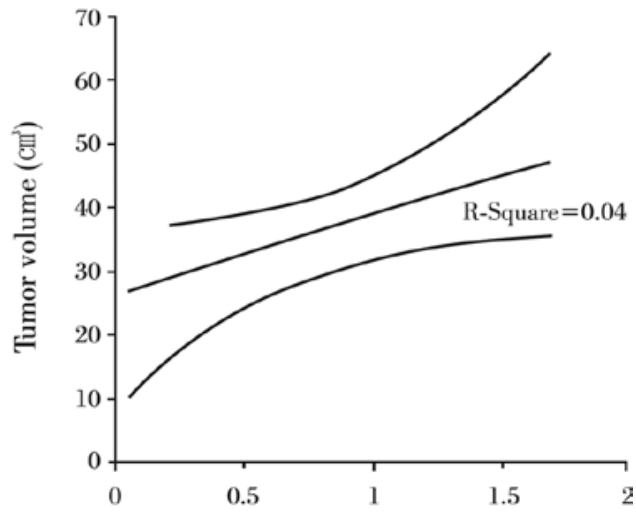

Granulin expression (ratio of OD)

Figure 2. Granulin expression in relation to tumor volume. (A) Tumor sizes were markedly larger in meningiomas with granulin than in those without granulin. (B) The amount of granulin was not correlated with tumor volume $(\mathrm{P}>0.05)$.

A

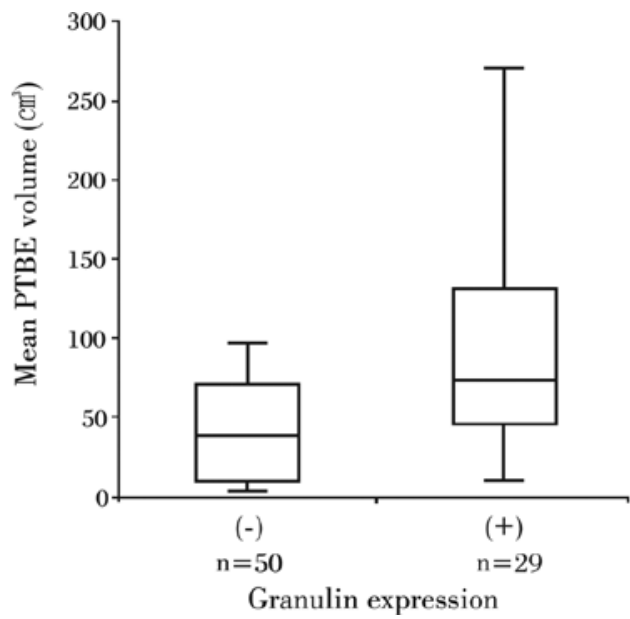

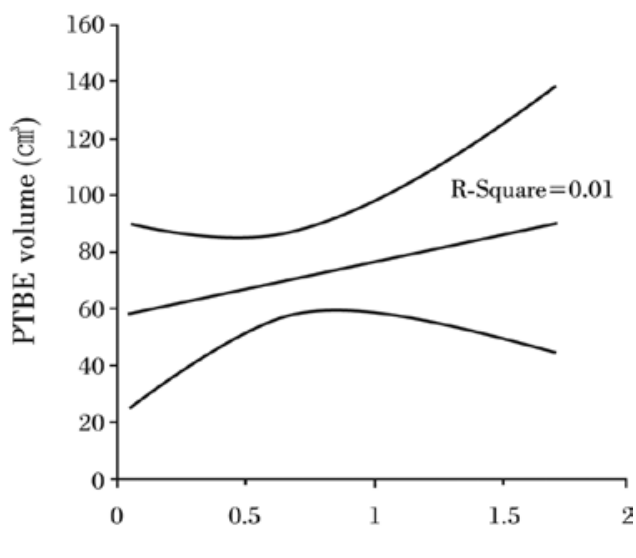

Granulin expression (ratio of OD)

Figure 3. Relationship between PTBE volume and granulin expression in meningiomas. (A) PTBE volume was significantly larger in meningiomas with granulin in comparison to those without granulin. (B) The amount of granulin was not correlated with tumor volume (P>0.05).

and progression appears to be complex and multifactorial (13). Compared to other well-established growth factors, such as insulin-like growth factor, VEGF and fibroblast growth factor, information about granulin is much more limited, although it has been shown that the granulin gene is readily induced when quiescent cells are aroused into a state of proliferation and motility, such as in neoplastic transformation, or in the case of tissue injury of dermal connective tissue (20).

Four isoforms of granulin, A, B, C and D, have been isolated from human inflammatory cells. Granulin A was found to be the most abundant and has been characterized in full using microsequencing techniques. Partial aminoterminal sequences were obtained for granulins B, C and D, and these sequences indicate that all four human granulins are closely related. A fifth human granulin, granulin F, has recently been isolated from urine (21). In humans, the granulin precursor is 593 amino acids long, and each of the five human granulins that have been isolated as individual peptides is represented in the common precursor. The human granulin gene is located on chromosome 17, and the proteincoding region of the granulin gene is constructed of 12 exons. The intronic splice sites are positioned approximately in the middle of each granulin motif such that, at the genetic level, the 12-cysteine motif is split into two hemigranulin subdomains $(22,23)$. Also of interest are the surprising parallels between the granulin and epidermal growth factor systems. There is no direct correlation between epidermal growth factor receptor overexpression and granulin-induced growth regulation. In a study of brain tumors it was found that granulin mRNA was expressed predominantly in glial cell tumors, while expression was not detected in non-tumor brain tissues. This finding suggests that granulin may play a role in the pathogenesis and/or malignant progression of primary brain tumors (9).

In a previous study, the highest levels of granulin were found in the placenta and the spleen, although levels were also high in several reproductive tissues, most notably the ovary, and also in the epidermis (24). Granulin modulates the growth of epithelial and mesenchymal cells in vitro, and high levels of expression have been found in several types of cancers (8-10). Overexpression of granulin has also been linked to the growth and tumorigenicity of human breast carcinoma $(11,12)$. Previous studies have shown that granulin expression occurs predominantly in epithelial cells, with little expression 
in mesenchymal cells, muscle or endothelium (25). In this study, we also observed granulin expression in meningiomas originating from mesenchymal cells.

Granulin E promotes neuronal survival and enhances neurite outgrowth in cultured neurons (26). The differential expression of granulin in human gliomas was confirmed by Northern blot analysis, which showed a transcript of $2.1-\mathrm{kb}$ expressed in $86 \%$ (18 of 21) of human gliomas. It is possible that granulin expression is mitigated by radiation and/or is related to higher malignancy and tumor progression (9). The results of our study showed that granulin expression was correlated to tumor size and PTBE development of intracranial meningiomas. This finding suggests that granulin may affect the progression of meningioma as it does in gliomas. However, one limitation of our study is that granulin was investigated at the mRNA level, and additional studies may be required to verify granulin expression at the protein level.

In conclusion, we confirmed the expression of granulin in intracranial meningiomas and found that its expression is correlated to tumor size and PTBE volume. This information provides a novel insight into the molecular biology of intracranial meningiomas and suggests a potential target for management of unresectable or malignant meningiomas. Further study is required to verify the role of granulin in the molecular biology of intracranial meningiomas.

\section{Acknowledgements}

This study was supported by the research fund of Hanyang University (HY-2006-C).

\section{References}

1. Cross M and Dexter TM: Growth factors in development, transformation and tumorigenesis. Cell 64: 271-284, 1991.

2. Morrison RS, Jarell AD and Schuster JM: Growth factors and brain tumors. In: Youmans Neurological Surgery. Winn HR (ed). Saunders, Philadelphia, pp725-738, 2004.

3. Lingood RM, Hsu DW, Efird JT and Pardo FS: TGF alpha expression in meningioma-tumor progression and therapeutic response. J Neurooncol 26: 45-51, 1995.

4. Braun B, Lange M, Oeckler R and Mueller MM: Expression of G-CSF and GM-CSF in human meningiomas correlates with increased tumor proliferation and vascularization. J Neurooncol 68: 131-140, 2004.

5. Lamszus K, Lengler U, Schmidt NO, Stavrou D, Ergün S and Westphal M: Vascular endothelial growth factor, basic fibroblast growth factor and placenta growth factor in human meningiomas and their relation to angiogenesis and malignancy. Neurosurgery 46: 938-948, 2000.

6. Bateman A and Bennett HP: The granulin gene family from cancer to dementia. Bioassay 31: 1245-1254, 2009.

7. Bateman A, Belcourt D, Benett HPJ, Hazure C and Solomon S: Granulins, a novel class of peptides from leukocytes. Biochem Biophys Res Commun 173: 1161-1168, 1993.

8. Donald CD, Laddu A and Chandham P, et al: Expression of progranulin and the epithelin/granulin precursor acrogranin correlates with neoplastic state in renal epithelium. Anticancer Res 21: 3739-3742, 2001.
9. Liau LM, Lallone RL and Seitz RS, et al: Identification of a human glioma-associated growth factor gene, granulin, using differential immuno-absorption. Cancer Res 60: 1353-1360, 2000.

10. Line AA, Stengrevics Z, Slucka GL, Jankevics E and Rees RC: Serological identification and expression analysis of gastric cancer-associated genes. Br J Cancer 86: 1824-1830, 2002.

11. Lu R and Serrero G: Inhibition of PC cell-derived growth factor (PCDGF, epithelin/granulin precursor) expression by antisense PCDGF cDNA transfection inhibits tumorigenicity of the human breast carcinoma cell line MDA-MB-468. Proc Natl Acad Sci USA 97: 3993-3998, 2000.

12. Lu R and Serrero G: Stimulation of PC cell-derived growth factor (epithelin/granulin precursor) expression by estradiol in human breast cancer cell. Biochem Biophys Res Commun 256: 204-207, 1999.

13. Otsuka S, Tamiya $\mathrm{T}$ and Ono Y, et al: The relationship between peritumoral edema and the exression of vascular endothelial growth factor and its receptors in intracranial meningiomas. J Neurooncol 70: 349-357, 2004.

14. Haddad GF, Al-Mefty O and Abdulrauf SI: Meningiomas. In: Youmans Neurological Surgery. Winn HR (ed). Saunders, Philadelphia, pp1099-1131, 2004.

15. Davidson B, Alejandro E, Florenes VA, Goderstad JM, Kristensen GB, Trope CG and Kohn EC: Granulin-epithelin precursor is a novel prognostic marker in epithelial ovarian carcinoma. Cancer 100: 2139-2147, 2004.

16. Davidson B, Risberg R, Reich R and Berner A: Effusion cytology in ovarian cancer - new molecular methods as aids to diagnosis and prognosis. Clin Lab Med 23: 729-754, 2003.

17. He Z and Bateman A: Progranulin (granulin-epithelin precursor, PC-cell derived growth factor, acrogranin) mediates tissue repair and tumorigenesis. J Mol Med 81: 600-612, 2003.

18. Jemal H, Murray T, Samuels A, Ghafoor A, Ward E and Thun MJ: Cancer Statistics 2003. CA Cancer J Clin 53: 5-26, 2003.

19. Ong CHP and Bateman A: Progranulin (granulin-epithelin precursor, PC-cell derived growth factor, acrogranin) in proliferation and tumorigenesis. Histol Histopathol 18: 1275-1288, 2003.

20. Hoque M, Young TM, Lee CG, Serrero G, Mathews MB and Pe'ery T: The growth factor granulin interacts with cyclin T1, and modulates p-TEFb-dependent transcription. Mol Cell Biol 23: $1688-1702,2003$

21. Sparro G, Galdenzi G, Eleuteri AM, Angeletti M, Schroeder W and Fioretti E: Isolation and $\mathrm{N}$-terminal sequence of multiple forms of granulins in human urine. Protein Expr Purif 10: 169-174, 1997.

22. Bhandari V and Bateman A: Structure and chromosomal location of the human granulin gene. Biochem Biophys Res Commun 188: 57-63, 1992.

23. Baba T, Hoff HB III, Nemoto H, Lee H, Orth J, Arai Y and Gertan GL: Acrogranin, an autosomal cysteine-rich glycoprotein, is the precursors of the growth-modulating peptides, granulin and epithelins and is expressed in somatic as well as male germ cells. Mol Reprod Dev 34: 233-243, 1993.

24. Bhandari V, Giad A and Bateman A: The cDNA structure, tissue distribution and cellular localization of the rat granulin precursors: a novel growth factor-like protein. Endocrinology 133: 2682-2689, 1993.

25. Bhandari V, Palfree RG and Bateman A: Isolation and sequence of the granulin precursor cDNA from human bone marrow reveals tandem cysteine-rich granulin domains. Proc Natl Acad Sci USA 89: 1715-1719, 1992.

26. Van Damme P, van Hoecke A, Lambrechts D, Vanacker P, Bogaert E, van Swieten J, Carmeliet P, van Den Bosch L and Robberecht W: Progranulin functions as a neurotrophic factor to regulate neurite outgrowth and enhance neuronal survival. J Cell Biol 181: 37-41, 2008. 